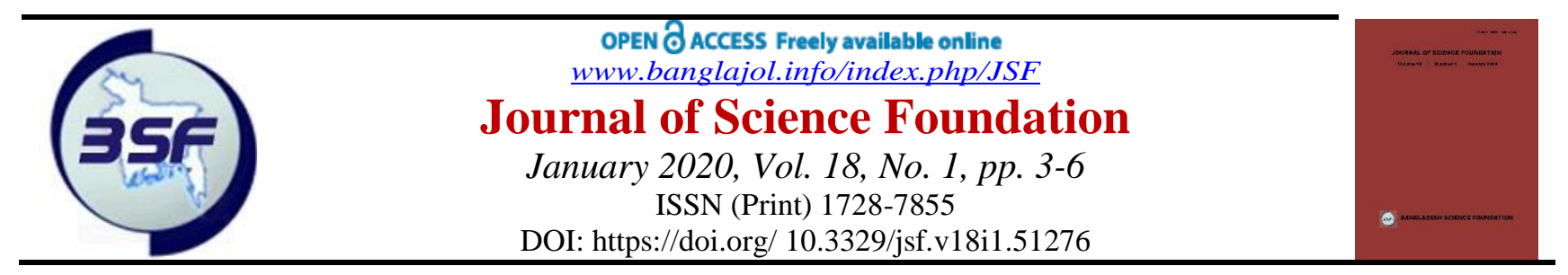

Original Article

\title{
Autonomic and Motor Involvement among the Patients Presented with Prolapse Lumbar Intervertebral Disc
}

\author{
Md. Rustom Ali ${ }^{1}$, Ayesha Afroz Chowdhury ${ }^{2}$, Md. Farhad Ahmed ${ }^{3}$, Md. Ibrahim Khalil ${ }^{4}$
}

\begin{abstract}
Background: Involvement of autonomic and motor nervous system are very crucial for the patients suffering from prolapse lumbar intervertebral disc. Objective: The purpose of the present study was to see the involvement of autonomic and motor nervous system of the patients suffering from prolapse lumbar intervertebral disc. Methodology: This cross-sectional study was carried out in the department of Neurosurgery at Bangabandhu Sheikh Mujib Medical University (BSMMU), Dhaka, Bangladesh from March 2006 to October 2007 for a period of one and half year. Prolapse lumbar intervertebral disc (PLID) patients who were admitted in the Department Neurosurgery at BSMMU, Dhaka, Bangladesh after clinical and radiological evaluation were selected as study population. The involvement of autonomic and motor nervous system were examined among the patients suffering from prolapse lumbar intervertebral disc. Result: A total of 59 hospital-admitted cases of PLID were included in the study. The mean age of the patients was $40.8 \pm 11.9$ years and the lowest and highest ages were 21 and 65 years respectively. Majority of the patients had intact bladder function which was $57(94.9 \%)$ cases and the remaining $2(3.4 \%)$ cases had incontinence of urine. More than half (54.2\%) of the subjects exhibited weak extensor hallucis longus test, while $30.5 \%$ had weak flexor digitalis longus test. Conclusion: In conclusion motor dysfunction is very high, but low rate of autonomic abnormalities are found among the patients suffering from prolapse lumbar intervertebral disc. [Journal of Science Foundation, January 2020;18(1):3-6]
\end{abstract}

Keywords: Autonomic involvement; motor involvement; prolapse lumbar intervertebral disc [Reviewed: 3 November 2019; Accepted on: 1 December 2019; Published on: 1 January 2020]

\section{Introduction}

Pain of prolapse lumbar intervertebral disc that is localized to the lower back and gluteal area often is associated with disk disease. Pain associated with nerve root involvement commonly radiates down the leg, particularly below the level of the knee. Pain with flexion, rotation, or prolonged sitting or standing, and sharp rather than dull pain are suggestive of disk disease (Baldwin 2007).

\footnotetext{
${ }^{1}$ Assistant Professor, Department of Neurosurgery, National Institute of Neurosciences \& Hospital, Dhaka, Bangladesh

${ }^{2}$ Assistant Professor, Department of Community Medicine, Sir Salimullah Medical College, Dhaka, Bangladesh

${ }^{3}$ Medical Officer, Department of Neurosurgery, National Institute of Neurosciences \& Hospital, Dhaka, Bangladesh

${ }^{4}$ Junior Consultant (Neurosurgery), Shahid Shiek Abu Naser Specialized Hospital, Khulna, Bangladesh
}

Correspondence: Dr. Md. Rustom Ali, Assistant Professor of Neurosurgery, National Institute of Neuroscience \& Hospital, Agargaon, Sher-E-Bangla Nagar, Dhaka-1207, Bangladesh; Email: malirustom@ gmail.com; Cell no.: +8801819127441

Copyright: (02020. Ali et al. Published by Journal of Science Foundation. This article is distributed under the terms of the Creative Commons Attribution 4.0 International CC BY-NC License (https://creativecommons.org/licenses/by-nc/4.0/). This license permits unrestricted use, distribution and reproduction in any medium, provided the original work is properly cited, you give appropriate credit to the original author(s) and is not used for commercial purposes 
The symptoms of disc injury depend upon the location of the disc tears and whether or not the spinal nerves or spinal cord are affected (Garfin 2007). When tearing of the annulus occurs within it's inner portion only, generally pain is not experienced. As previously stated, this is because the inner regions of the annulus lack pain receptors. When tearing of the annulus occurs in the outer annular fibers, mild to excruciating pain is felt in a generalized manner. If a lumbar disc is affected, for instance, diffuse low back pain with associated paraspinal muscle spasm is typical (Garfin 2007).

When numerous partial tears coalesce to form tears which run clear through the thickness of the annulus, the gel-like nucleus is able to escape the disc. If a spinal nerve or the spinal cord is contacted the individual may experience symptoms of pain, numbness, tingling and/or weakness within either or both lower extremities. In rare cases patients may lose the ability to control bowel and bladder functions. If this occurs, immediate medical intervention is required as the condition can become permanent (Garfin 2007).

The cauda equina syndrome may result from a very large central disc herniation that compresses the entire bundles of rootlets traversing the region of herniation. While radiculopathy may coexist, the patient complains of peripheral numbness, inability to void secondary to flaccid bladder, and/or incontinence. Recognition of this syndrome is paramount as its presence demands work-up and treatment (Wolfla 2005). The purpose of the present study was to see the involvement of autonomic and motor nervous system are very crucial for the patients suffering from prolapse lumbar intervertebral disc.

\section{Methodology}

This was a cross-sectional study. This study was carried out in the department of Neurosurgery at Bangabandhu Sheikh Mujib Medical University (BSMMU), Dhaka, Bangladesh from March 2006 to October 2007 for a period of one and half year. PLID patients who were admitted in the Department Neurosurgery at BSMMU, Dhaka after clinical and radiological evaluation. Convenient and purposive sampling was applied. Patients who were clinical diagnosis of PLID and MRI done for confirmation were selected as study population. Clinical diagnosis of PLID patients but refuse MRI for confirmation were excluded from this study. The clinical features involving the autonomic and motor nervous system were examined and were recorded. The research protocol was approved by the department of Neurosurgery, BSMMU. On admission, detailed history of the patients was taken and thorough general and neurological examinations were performed by the researcher. Then the data collection sheet was filled accordingly. Data were processed and analyzed using SPSS (Statistical Package for Social Sciences) version 22.0.

\section{Result}

A total of 59 hospital-admitted cases of PLID were included in the study. Of the 59 patients $20.3 \%$ cases were below 30 years; $8.5 \%$ cases were in between 30 to 35 years; $15.3 \%$ cases were in 35 to 40 years; another $15.3 \%$ cases were in 40 to 45 years and $40.7 \%$ cases were 45 or above 45 years of age. The mean age of the patients was $40.8 \pm 11.9$ years and the lowest and highest ages were 21 and 65 years respectively (Table 1).

Table 1: General Characteristics of the Patients $(n=59)$

\begin{tabular}{|l|c|c|}
\hline Age Group & Frequency & Percent \\
\hline Less Than 20 Years & 0 & 0.0 \\
\hline 20 to 25 Years & 4 & 6.7 \\
\hline 25 to 30 Years & 8 & 13.5 \\
\hline 30 to 35 Years & 05 & 8.5 \\
\hline 35 to 40 Years & 09 & 15.3 \\
\hline 40 to 45 Years & 09 & 15.3 \\
\hline More Than 45 Years & 24 & 40.7 \\
\hline Total & $\mathbf{5 9}$ & $\mathbf{1 0 0 . 0}$ \\
\hline
\end{tabular}

* Mean age $=(40.8 \pm 11.9)$ years; range $=(21-65)$ years

Majority of the patients had intact bladder function which was 57(94.9\%) cases and the remaining 2(3.4\%) cases had incontinence of urine. However, the involvement of bowel was not found among the study population (Table 2). 
Table 2: Distribution of patients by Bowel/Bladder Habit $(n=59)$

\begin{tabular}{|l|c|c|}
\hline Bladder Involvement & Frequency & Percent \\
\hline Intact & 57 & 96.6 \\
\hline Incontinence/Retention & 2 & 3.4 \\
\hline Total & $\mathbf{5 9}$ & $\mathbf{1 0 0 . 0}$ \\
\hline
\end{tabular}

None of the hip group muscles was found weak on motor function test, while $3(5.1 \%)$ of the knee group muscles were found weak. More than half $(54.2 \%)$ of the subjects exhibited weak extensor hallucis longus test, while $30.5 \%$ had weak flexor digitalis longus test (Table 3).

Table 3: Distribution of Patients by Motor Function Test $(\mathbf{n}=59)$

\begin{tabular}{|l|c|c|}
\hline Motor Function Test & Frequency & Percent \\
\hline Hip group & & \\
Weak & 0 & 0.0 \\
Normal & 59 & 100.0 \\
\hline Knee group & 3 & 5.1 \\
Weak & 55 & 94.9 \\
Normal & & \\
EHL & 32 & 54.2 \\
Weak & 27 & 45.8 \\
Normal & & \\
\hline FDL & 18 & 30.5 \\
Weak & 41 & 69.5 \\
\hline
\end{tabular}

Of the total 59 patients only $4(6.8 \%)$ had diminished knee jerk and the rest of 55(93.2\%) had normal knee jerk. However, out of 59 cases 33(55.9\%) patients had diminished ankle jerk and the rest of the 26(44.1\%) cases had normal ankle jerk. In case of planter jerk, all the cases (100.0\%) exhibited flexor response, Extensor planter response was not found in any of the study population (Table 4).

Table 4: Distribution of Patients by Reflex Function (n=59)

\begin{tabular}{|l|c|l|}
\hline Reflex function & Frequency & Percent \\
\hline Knee jerk & & \\
Normal & 55 & 93.2 \\
Diminished & 04 & 6.8 \\
\hline Ankle jerk & & \\
Normal & 26 & 44.1 \\
Diminished & 33 & 55.9 \\
\hline Planter & & \\
response & & \\
Flexor & 59 & 100.0 \\
Extensor & 00 & 0.0 \\
\hline
\end{tabular}

\section{Discussion}

Lumbar disc herniations occur most commonly from $3^{\text {rd }}$ to $5^{\text {th }}$ decade with peak incidence in the $4^{\text {th }}$ decade of life and less commonly in the $6^{\text {th }} \& 7^{\text {th }}$ decade (Hardy and Ball 2004). Lumbar disc herniations are most common at the level of L4 - L5 and L5 -S1 levels. Less than 5.0\% of disc herniations occur at L1, L2 \& L3 levels. The earliest evidence of root involvement, in a lumbar disc prolapse, is radiating pain along the course of the sciatic nerve, commonly called sciatica (Goel and Panday 1996).

The present study showed that the mean age of the PLID cases was 40.8 years with lowest and highest ages were 21 and 65 years respectively which is consistent with the findings two other studies where mean ages of the study patients were 42.9 years and 41.6 years respectively (Chawalparti et al., 2006; Kermani, 2004). Lumbar disc herniation in childhood and adolescence is a relatively rare condition. Only 1 to $3 \%$ of lumbar disc herniation occurs in individuals under 21 years of age (Fisher and Saunders, 1981). Sex distribution of the lumbar disc prolapse in the United States and other developed countries is almost equal (Baldwin 2006; Windsor 2007) which sharply contrast with male, female ratio (11:1) observed in the present study. 
The reason of such wide variation in male to female ratio is likely due to proportionately higher bed allocation for male in the neurosurgery ward. Besides this, in the sociocultural context of our country female patients get less preference for sophisticated medical treatment which might be another reason of low inclusion of female patients in our study.

Cauda equina syndrome or saddle anaesthesia is a sever neurological disorder that can result from lumbar disc herniation with excessive compression on the cauda equina. Cauda equina syndrome is a serious complication of lumbar disc herniation that requires an emergency surgery. Cauda equina syndrome occurs in approximately $2 \%$ of the cases of herniated lumbar disc (Milette et al., 1999). This finding is in close agreement with finding of the present study where 2(3.4\%) cases out of 59 had cauda equina syndrome and they required urgent surgery.

Regarding Motor function test, 54.0\% patients showed L5 root involvement (EHL), 30.0\% S1 root involvement and only 5.0\% L3 involvement. The diagnostic value of sensibility test for patients with lumbar disc herniation is debatable. The presence of a reduction in sensibility in such patients varies between 21 and $88.0 \%$ (Peeters et al., 1998). The reported frequency of loss in individuals with documented herniated lumbar discs has range from 21 to 84\% (Weise et al., 1985). In our study, sensory impairment along the L4 distribution was 2\%, L5 distribution 20\% and S1 distribution 14\%. This finding corresponds with finding of Peeters et al (1998) and Weise et al (1985).

\section{Conclusion}

In conclusion motor dysfunction is found among the study population of which extensor hallucis longus test, flexor digitalis longus test are weak. However, diminished knee jerk and ankle jerk are also reported among the study population. Extensor planter response is not found any of the study population. Furthermore, low rate of autonomic abnormalities are found among the patients suffering from prolapse lumbar intervertebral disc. A large scale study should be carried out to get the real scenario.

\section{References}

Baldwin J. Lumbar (Intervertebral) Disk Disorder, e, Medicine, Retrieve: October 19 2007; From e medicine World Medical Library database, 2007

Chawalparit O, Churojana A, Chiewvit P, Thanapipatsir S, Vamvanij V, Charnchaowanish P. The limited protocol MRI in diagnosis of lumbar disc herniation. Journal-Medical Association Of Thailand. 2006;89(2):182

Fisher RG, Saunders RL. Lumbar disc protrusion in children. Journal of neurosurgery. 1981;54(4):480-3

Garfing SR. Sciatica: Symptoms and possible Causes. Retrieve: October 19 2007; From University of California, San Diego, Library database, 2007

Gool A, Panday SK. Lumbar Disc Protrusion. In: Text- Book of Neurosurgery, $2^{\text {nd }}$ edn. Ramamurthi PB, Tandon PNBI. Churchill Living stone, New Delhi, 1996;2:743-756

Hardy RW, Ball, PA. Treatment of Disk disease of the lumbar spine. In: YOUMANS Neurological surgery, Winn HR (eds) $5^{\text {th }}$ edn Saunders. USA 2004;4:4507-4520

Milette PC, Fontaine S, Lepanto L, Cardinal É, Breton G. Differentiating lumbar disc protrusions, disc bulges, and discs with normal contour but abnormal signal intensity: Magnetic resonance imaging with discographic correlations. Spine. 1999;24(1):44-53

Peeters GG, Aufdemkampe G, Oostendorp RA. Sensibility testing in patients with a lumbosacral radicular syndrome. Journal of Manipulative and physiological Therapeutics. 1998;21(2):81-8

Reihani-Kermani H. Correlation of clinical presentation with intraoperative level diagnosis in lower lumbar disc herniation. Annals of Saudi medicine. 2004;24(4):273-5

Weise MD, Garfin SR, Gelberman RH, Katz MM, Thorne RP. Lower-extremity sensibility testing in patients with herniated lumbar intervertebral discs. JBJS. 1985;67(8):1219-24

Windsor, RE. Lumbosacral Disc, Injuries. e Medicine Retrieve October 19,2007 From, E Medicine World Medical Library data base, 2005

Wolfa, CE. Lumbar Disc Herniaton, Principal of Neurosurgery. $2^{\text {nd }}$ Edn. Rengachary Setti, Ellenboggen Richandg, Elsevir Mosby U.S.A. 2005;753-760 